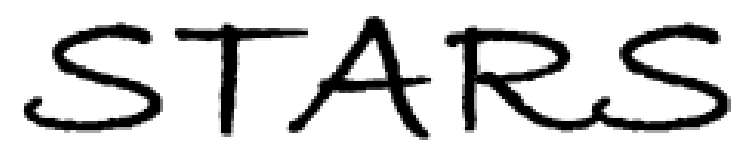

University of Central Florida

STARS

$1-1-2013$

\title{
Wireless passive polymer-derived SiCN ceramic sensor with integrated resonator/antenna
}

Yan Li

Yuxi Yu

Haisheng San

Yansong Wang

Linan An

University of Central Florida

Find similar works at: https://stars.library.ucf.edu/facultybib2010 University of Central Florida Libraries http://library.ucf.edu

This Article is brought to you for free and open access by the Faculty Bibliography at STARS. It has been accepted for inclusion in Faculty Bibliography 2010 s by an authorized administrator of STARS. For more information, please contactSTARS@ucf.edu.

\section{Recommended Citation}

Li, Yan; Yu, Yuxi; San, Haisheng; Wang, Yansong; and An, Linan, "Wireless passive polymer-derived SiCN ceramic sensor with integrated resonator/antenna" (2013). Faculty Bibliography 2010s. 4303.

https://stars.library.ucf.edu/facultybib2010/4303

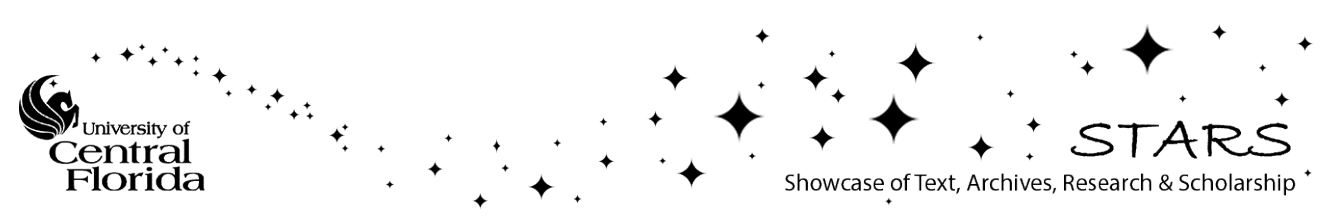




\section{Wireless passive polymer-derived SiCN ceramic sensor with integrated resonator/ antenna}

Cite as: Appl. Phys. Lett. 103, 163505 (2013); https://doi.org/10.1063/1.4824827

Submitted: 09 July 2013 . Accepted: 24 September 2013 . Published Online: 16 October 2013

Yan Li, Yuxi Yu, Haisheng San, Yansong Wang, and Linan An
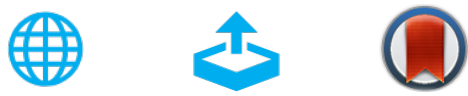

View Online

Export Citation

CrossMark

\section{ARTICLES YOU MAY BE INTERESTED IN}

On electric conduction of amorphous silicon carbonitride derived from a polymeric precursor Applied Physics Letters 102, 231902 (2013); https://doi.org/10.1063/1.4809825

Silicoboron-carbonitride ceramics: A class of high-temperature, dopable electronic materials Applied Physics Letters 78, 3076 (2001); https://doi.org/10.1063/1.1370540

On electronic structure of polymer-derived amorphous silicon carbide ceramics Applied Physics Letters 104, 221902 (2014); https://doi.org/10.1063/1.4881139

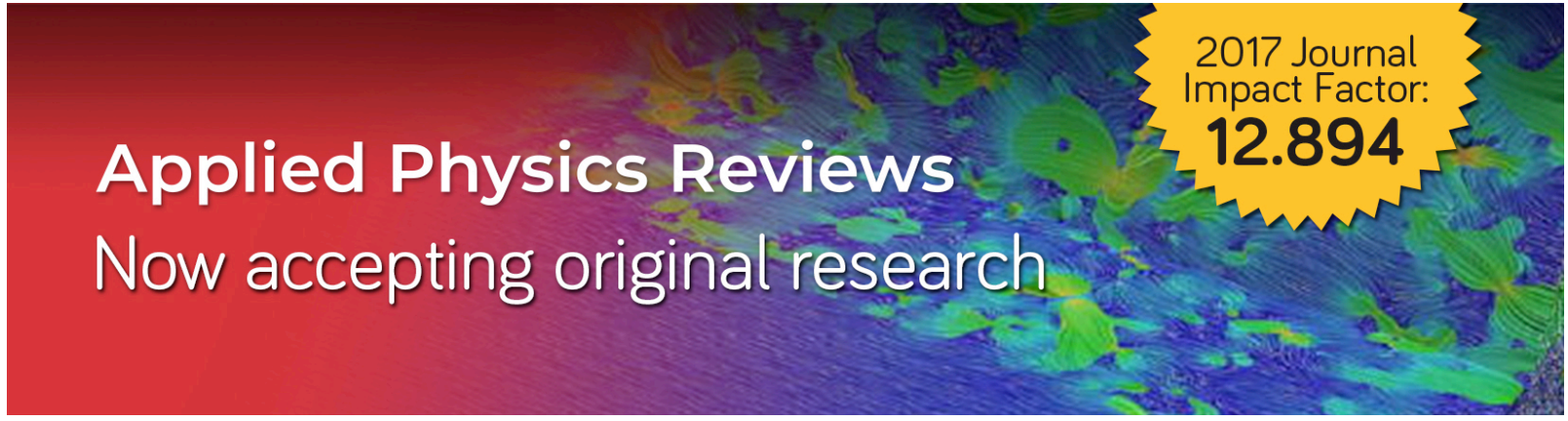




\title{
Wireless passive polymer-derived SiCN ceramic sensor with integrated resonator/antenna
}

\author{
Yan Li, ${ }^{1,2,3,4}$ Yuxi Yu, ${ }^{2,3, a)}$ Haisheng San, ${ }^{4}$ Yansong Wang, ${ }^{5}$ and Linan $\mathrm{An}^{6}$ \\ ${ }^{1}$ Department of Physics, Xiamen University, Xiamen 361005, China \\ ${ }^{2}$ Department of Materials Science and Engineering, College of Materials, Xiamen University, \\ Xiamen 361005, China \\ ${ }^{3}$ Shenzhen Research Institute of Xiamen University, Shenzhen 518057, China \\ ${ }^{4}$ Pen-Tung Sah Institute of Micro-Nano Science and technology, Xiamen University, Xiamen 361005, China \\ ${ }^{5}$ Key Laboratory of Optical System Advanced Manufacturing Technology, Changchun Institute of Optics, \\ Fine Mechanics and Physics, CAS, Changchun 130033, China \\ ${ }^{6}$ Advanced Materials Processing and Analysis Center, University of Central Florida, Orlando, \\ Florida 32816, USA
}

(Received 9 July 2013; accepted 24 September 2013; published online 16 October 2013)

\begin{abstract}
This paper presents a passive wireless polymer-derived silicon carbonitride $(\mathrm{SiCN})$ ceramic sensor based on cavity radio frequency resonator together with integrated slot antenna. The effect of the cavity sensor dimensions on the Q-factor and resonant frequency is investigated by numerical simulation. A sensor with optimal dimensions is designed and fabricated. It is demonstrated that the sensor signal can be wirelessly detected at distances up to $20 \mathrm{~mm}$. Given the high-temperature stability of the $\mathrm{SiCN}$, the sensor is very promising for high-temperature wireless sensing applications. (C) 2013 AIP Publishing LLC. [http://dx.doi.org/10.1063/1.4824827]
\end{abstract}

Sensors that can operate in high-temperature harsh environments are highly desired for varied high-temperature systems, such as turbine engines. These sensors will be used to acquire physical and chemical information from the systems for monitoring their operation processes and structural component conditions, thus to improve the efficiency and safety of the systems. However, developing such sensors is not a trivial matter. The biggest technical challenge is that the sensors must survive the harsh environments associated with the systems, including high temperatures, high pressures, corrosive species, and sometime irradiations. ${ }^{1-6}$ While SiC-based sensors have been extensively developed and are now commercially available, they cannot be used at temperatures higher than $500^{\circ} \mathrm{C} .^{7,8}$ Developing sensors that can work at even higher temperatures requires new sensor design and new materials.

Recently, a wireless passive temperature sensor concept, based on a simple radio frequency (RF) cavity resonator, has been proposed. ${ }^{9,10}$ It is demonstrated that such a sensor can work up to $1000^{\circ} \mathrm{C}$ by using aluminum oxide as the sensing material. While this work provides a possibility of wireless high-temperature sensors, the detailed sensor design has not been reported in that work. In addition, alumina is not suitable for long-term high-temperature applications due to its high conductivity (leading to high energy loss) and decreased mechanical properties at high temperatures.

On the other hand, it has been demonstrated that polymerderived ceramics (PDCs) synthesized by pyrolyzing polymeric precursors are very promising for high-temperature sensor applications. ${ }^{6,11}$ Previous studies revealed that these materials exhibited a set of excellent structural and functional properties, such as outstanding high-temperature stability, ${ }^{12}$ improved

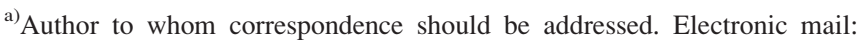
yu_heart@xmu.edu.cn
}

oxidation/corrosion resistance, ${ }^{12-14}$ excellent creep resistance, ${ }^{15}$ high-temperature semiconducting behavior, ${ }^{16,17}$ and huge piezoresistivity. ${ }^{18-21}$ In particular, it is discovered most recently that the dielectric constant of silicon carbonitride $(\mathrm{SiCN})$ varies with temperature. ${ }^{22,23}$ It is this last property that makes the materials very promising for wireless temperature sensor applications.

In this paper, we report a detailed design on passive wireless temperature-sensor based on RF resonator. The effect of various parameters on the sensor performance (resonant frequency and Q value) is investigated numerically. Finally, a prototype sensor is synthesized and demonstrated by using a polymer-derived $\mathrm{SiCN}$ ceramics as the sensing materials.

As the core of the sensor, the model material silicon carbonitride ceramic was made first. SiCN ceramic, was synthesized by using a lab-made polysilazane (PSN) as the main polymeric precursor and commercially available dicumyl peroxide (DCP) as the radical initiator. First, 5 wt. \% DCP was mixed with PSN by magnetically stirring at $40^{\circ} \mathrm{C}$ for $1 \mathrm{~h}$ to achieve uniform mixing. The mixture was then cross-linked at $140^{\circ} \mathrm{C}$ in air to form an infusible solid polymer. The obtained solid was crushed into fine powder of $\sim 1 \mu \mathrm{m}$ using highenergy ball milling, and then compressed into discs with the uniaxial pressing at $16 \mathrm{MPa}$ at room temperature. The discs were pyrolyzed at $1000^{\circ} \mathrm{C}$ for $4 \mathrm{~h}$ in a tube furnace under a flow of ultra-high-purity nitrogen to convert them to ceramic disks of $10-18 \mathrm{~mm}$ in diameter and $1-5 \mathrm{~mm}$ in height. Xray diffraction (XRD) analysis revealed that the obtained material is amorphous without any detectible diffraction peak. The dielectric properties of the obtained $\mathrm{SiCN}$ ceramic were measured by shorted waveguide and cavity perturbation methods using an Agilent $20 \mathrm{GHz}$ VNA (HP8720ES) at room temperature. $^{24,25}$ The measured dielectric constant and loss tangent of the $\mathrm{SiCN}$ ceramic are 3.805 and 0.009 at $9.98 \mathrm{GHz}$, respectively. 


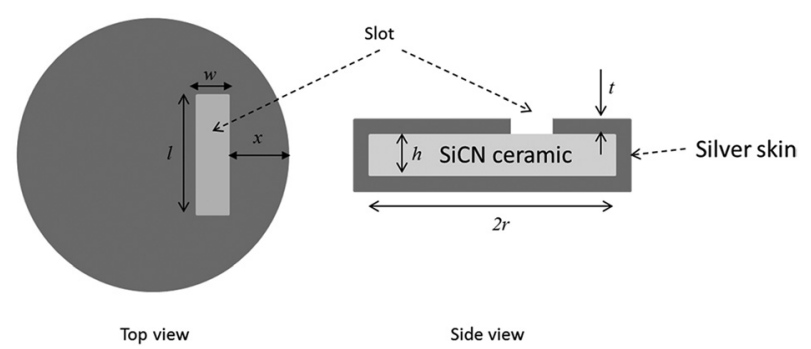

FIG. 1. Schematic of an open-ended cycle resonator/slot antenna.

The geometry of the proposed sensor was shown in Fig. 1 schematically: a SiCN ceramic disc with radius $r$ and thickness $h$; a metal (in this paper, we use silver) skin of thickness $t$, which covers the disc; a slot with width $w$ and length $l$, and the distance of the slot from the edge of the disc $x$. The slot worked as both RF signal receiver and transmitter is used to decrease the size of the sensor. The design of the sensor is to find out the optimal parameters that lead to highest possible Q-factor. The parameters that affect the $\mathrm{Q}$ value of the sensor are dielectric constant and dielectric loss of the sensing material (in our case, it is SiCN ceramic), the thickness of the silver skin, the dimensions and position of the slot, and the dimensions of the disc. Since the dielectric parameters of the $\mathrm{SiCN}$ ceramic are fixed, in this paper, all simulations are based on the properties of the SiCN ceramic. We will investigate the effect of the other parameters on the Q-factor.

We first studied the effect of silver skin thickness. In general, the thickness of the metal skin should be thicker than ten times of the skin depth in order to eliminate the skin effect. For silver, the skin depth can be calculated by ${ }^{26}$

$$
\delta=\frac{0.064}{\sqrt{f}}(\mathrm{~m})
$$

where $\delta$ is the skin depth of silver and $f$ is the measurement frequency $(\mathrm{Hz})$. For frequency between $1-15 \mathrm{GHz}$ (which is the target working frequency of the proposed sensor), the thickness of the silver is calculated to be $\sim 5.23-20.48 \mu \mathrm{m}$. Fig. 2 shows the effect of silver skin thickness on the unloaded Q-factor $\left(\mathrm{Q}_{\mathrm{U}}\right)$, simulated by using the high

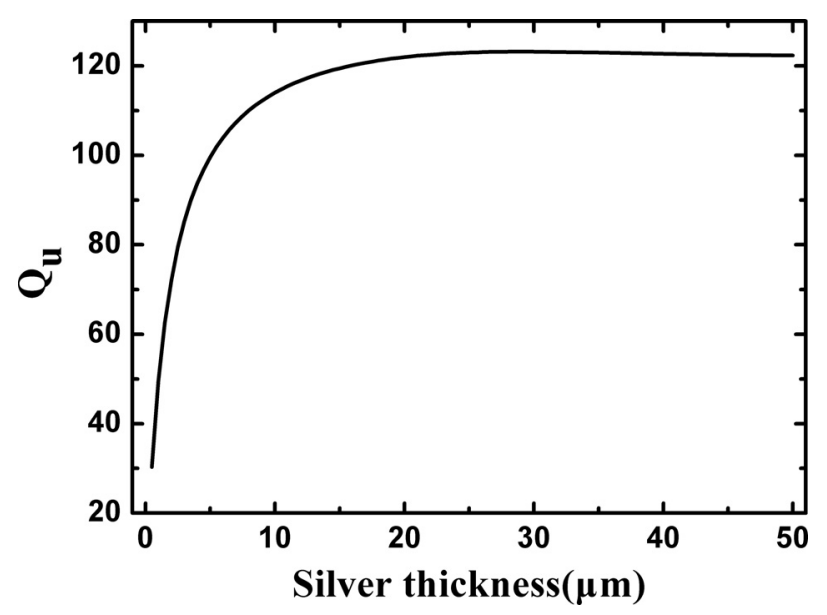

FIG. 2. Simulated $\mathrm{Q}_{\mathrm{u}}$ as a function of silver skin thickness (cylinder size: $\mathrm{r}=5.66 \mathrm{~mm}$ and $\mathrm{h}=1.1 \mathrm{~mm})$. frequency structure simulator (HFSS) at $f=10 \mathrm{GHz}$ (the simulation did not consider the effect of the $\mathrm{SiCN}$ ). It is seen that the $\mathrm{Q}_{\mathrm{U}}$ increases with the increase of thickness at beginning, and become unchanged when the thickness is more than $\sim 20 \mu \mathrm{m}$, which is consistent with the result calculated from Eq. (1). Consequently, in this research the silver coating of $25 \mu \mathrm{m}$ will be used to fabricate the sensor in next section.

We then investigate the effect of the other parameters on the $\mathrm{Q}$ value. For the sensor structure shown in Fig. 1, the load Q-factor $\left(\mathrm{Q}_{\mathrm{L}}\right)$ comprises of two parts: radiation $\mathrm{Q}$-factor $\left(\mathrm{Q}_{\mathrm{r}}\right)$ and unloaded $\mathrm{Q}$-factor $\left(\mathrm{Q}_{\mathrm{U}}\right)$, which can be related together by ${ }^{10}$

$$
\frac{1}{Q_{L}}=\frac{1}{Q_{U}}+\frac{1}{Q_{r}} .
$$

$\mathrm{Q}_{\mathrm{U}}$ includes the effects from the loss of the dielectric material and the loss of the metal; and $\mathrm{Q}_{\mathrm{r}}$ is due to the radiation through the slot antenna.

The unloaded Q-factor and resonance frequency $(f)$, which do not include the effect of the slot, can be calculated by $^{22}$

$$
\begin{gathered}
Q_{U}=\left(\frac{1}{Q_{S i C N}}+\frac{1}{Q_{A g}}\right)^{-1} \\
=\tan \delta+\left(2+\frac{2 r}{h}\right) \sqrt{\frac{2 \pi f \mu_{0}}{2 \sigma}} / \chi_{01} \sqrt{\frac{\mu_{0}}{\varepsilon_{0} \varepsilon_{r}}} \\
f=\frac{1}{2 \pi \sqrt{\varepsilon_{0} \mu_{0} \varepsilon_{r}}} \frac{\chi_{01}}{r}
\end{gathered}
$$

where $\varepsilon_{0}$ and $\mu_{0}$ are the permittivity and permeability of free space, respectively; $\chi_{01}$ is the first root of Bessel function of the first kind $J_{0}(\mathrm{z})$, i.e., $2.405 ; \varepsilon_{\mathrm{r}}$ and $\tan \delta$ are the dielectric constant and loss tangent of the dielectric material, respectively; $\sigma$ is the bulk conductivity of the silver, i.e., $6.3 \times 10^{7} \mathrm{~S} / \mathrm{m} ; r$ and $h$ are the radius and height of the SiCN disc, respectively. It is seen that for a given dielectric material, the $\mathrm{Q}_{\mathrm{U}}$ is only affected by the dimensions of the sensor. In this work, we set the dimensions of the SiCN disc to be $r=5.66 \mathrm{~mm}$ and $h=1.1 \mathrm{~mm}$. The resonant frequency of the cylinder resonator is then calculated to be $10.6 \mathrm{GHz}$ by using Eigenmode simulation in HFSS and $\mathrm{Q}_{U}$ to be 122. It is known that for a resonator with its thickness less than its diameter, the dominant resonance mode is $\mathrm{TM}_{010} \cdot{ }^{27}$

$\mathrm{Q}_{\mathrm{L}}$ of the resonator can be calculated using the insertion loss method 9,10

$$
Q_{L}=\frac{f_{0}}{\Delta f_{3 d B}} \frac{1}{1-\operatorname{mag}\left(S_{21}\left(\omega_{0}\right)\right)} .
$$

Two open-ended coaxial probes were used to calculate the transmission coefficient $\left(S_{21}\right)$ in order to get the $Q_{L}$. The $\mathrm{Q}_{\mathrm{r}}$ can then be calculated using Eq. (2). Fig. 3 shows the effect of the dimensions and location of the slot antenna on $\mathrm{Q}_{\mathrm{r}}$. It is seen that $\mathrm{Q}_{\mathrm{r}}$ and resonance frequency are decreasing with the increase of the length of the slot (Fig. 3(a)); while $Q_{r}$ is strict decreasing with the increase of the width of the slot, but resonance frequency is decreasing with the increase 


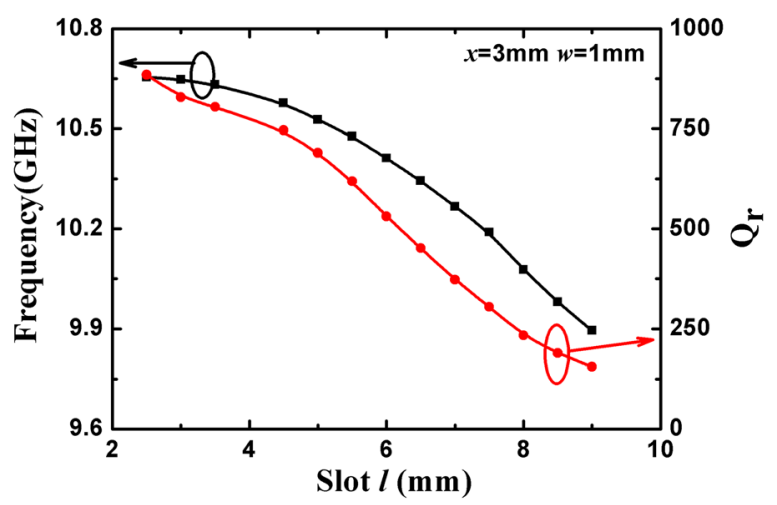

(a)

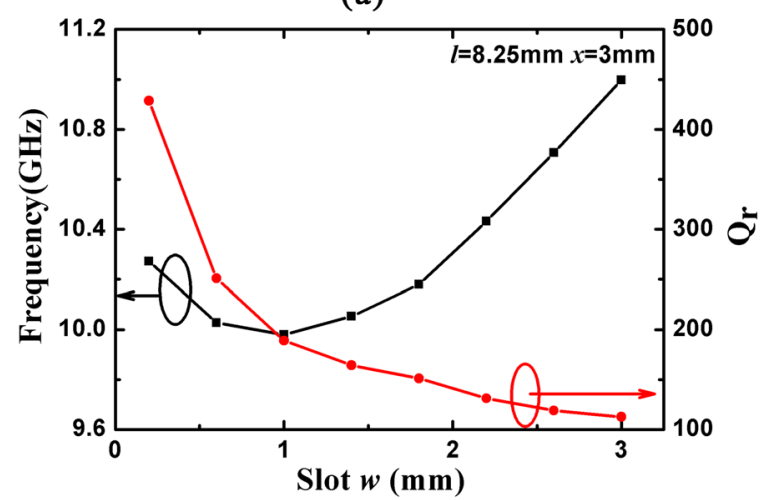

(b)

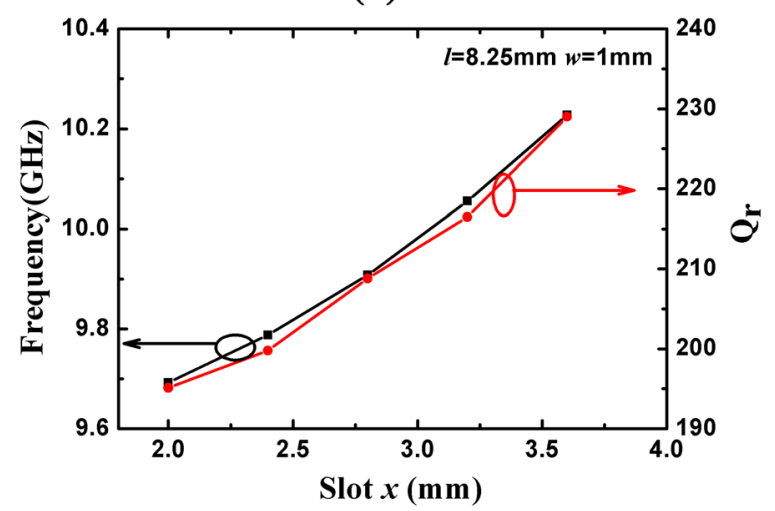

(c)

FIG. 3. The relationship of simulated $\mathrm{Q}_{\mathrm{r}}$ and resonance frequency with (a) slot lengths $l$, (b) widths $w$, and (c) $\operatorname{slot} x$.

of the width of the slot first, and then increasing with the increase of the width of the slot (Fig. 3(b)). $\mathrm{Q}_{\mathrm{r}}$ and resonance frequency are increasing with the position of the slot closing to axis (Fig. 3(c)). In model $\mathrm{TM}_{010}$, the electric field is parallel to the $\mathrm{Z}$ axis, while the magnetic field is perpendicular to the $\mathrm{Z}$ axis. When the slot moves away from the edge of the cylinder, the coupling between the cylinder resonance and the slot become stronger, so $\mathrm{Q}_{\mathrm{r}}$ increases with increasing $x$.

The maximum energy coupling between the slot antenna and resonator occurs when $\mathrm{Q}_{\mathrm{r}}$ is equal to $\mathrm{Q}_{\mathrm{U}}$. According to the result of Fig. 3, the desired size of the slot was selected to 8.5 and $1 \mathrm{~mm}$, and $x$ was set as $3 \mathrm{~mm}$. From this response, $\mathrm{Q}_{\mathrm{L}}$ of the resonator/antenna is found to be 64 using Eq. (5), which implies $\mathrm{Q}_{\mathrm{r}}$ of 134 using Eq. (2), very close to $\mathrm{Q}_{\mathrm{U}}$ of 122. The cavity resonant frequency is slightly detuned down to $9.98 \mathrm{GHz}$ due to the slot antenna loading effect.

The dimensions of the cylinder resonator can be changed readily in order to scale to other frequency bands based on the frequency characteristics of the engine. Fig. 4 shows the frequency and $\mathrm{Q}_{\mathrm{L}}$ corresponding to the peak in the simulated $S_{21}$ for different cylinder radius and height at the same slot antenna size. The frequency changes from 10.33 to $9.57 \mathrm{GHz}$ for different combinations of cylinder radius $(5.4-6 \mathrm{~mm})$. Though the resonance frequency practically kept same (9.85-9.99) at the height range from 0.3 to $2 \mathrm{~mm}$, the $\mathrm{Q}_{\mathrm{L}}$ decreases quickly with the increase of the height.

Following the guide of the simulation result, the sensor with the compact slot antenna was made. To wirelessly detect the resonant frequency of the cylinder resonator, an $\mathrm{X}$-band open-ended waveguide (OEWG, 8-12.4 GHz) with cross-sectional dimensions of $22.86 \times 10.16 \mathrm{~mm}$ is used to transmit a wide-band signal and receive reflected signals from the resonator/antenna. The gain of this OEWG is around $6 \mathrm{dBi}$ within the frequency of operation. As demonstrated in Refs. 9 and 10, two sources were reflected back to the OEWG: one is scattered wave by the ground plane of antenna; the other is due to the energy coupled to the cylinder resonance through the slot antenna, and then re-radiated. It is difficult to distinguish the resonant behavior of the sensor due to super-position of reflections from the OEWG, and the reradiated waves from the resonator. Therefore, timedomain (TD) gating was used to isolate the response from the sensor itself. ${ }^{28}$ Fig. 5 shows measured $S_{11}$ responses in TD for the OEWG with and without the resonator when the sensor is putted at the OEWG using a Network Analyzer (AV3629D, The 41st Institute of China Electronics Technology Group Corporation). Measurement system is calibrated using AV32117. The gating start time is set to be $1.0 \mathrm{~ns}$, and the gating stop time is set to be $15 \mathrm{~ns}$ where the two curves in Fig. 5 intersect each other. The measurement is carried out at the similar gating procedures for different sensing distances.

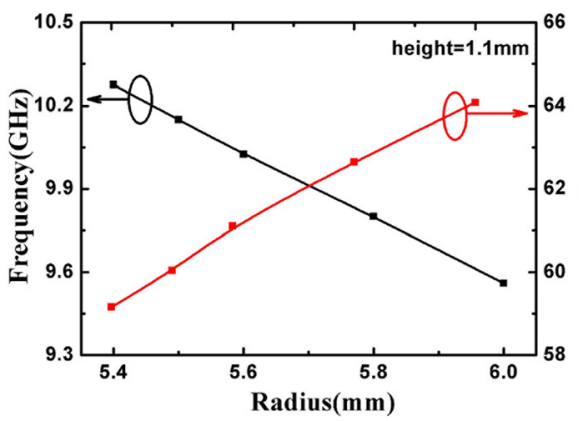

(a)

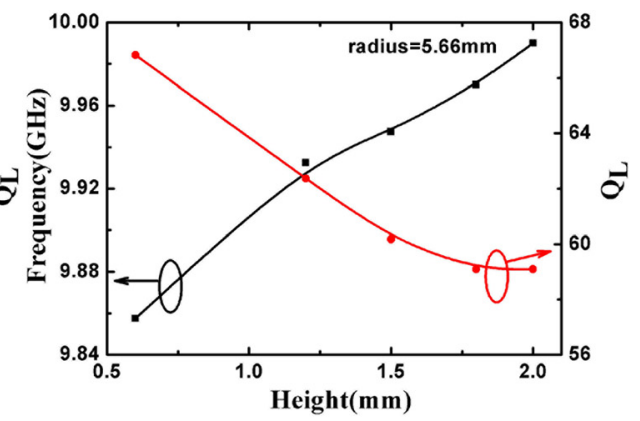

(b)
FIG. 4. Simulated $\mathrm{Q}_{\mathrm{L}}$ and resonance frequency for different cylinder (a) radius and (b) height. 


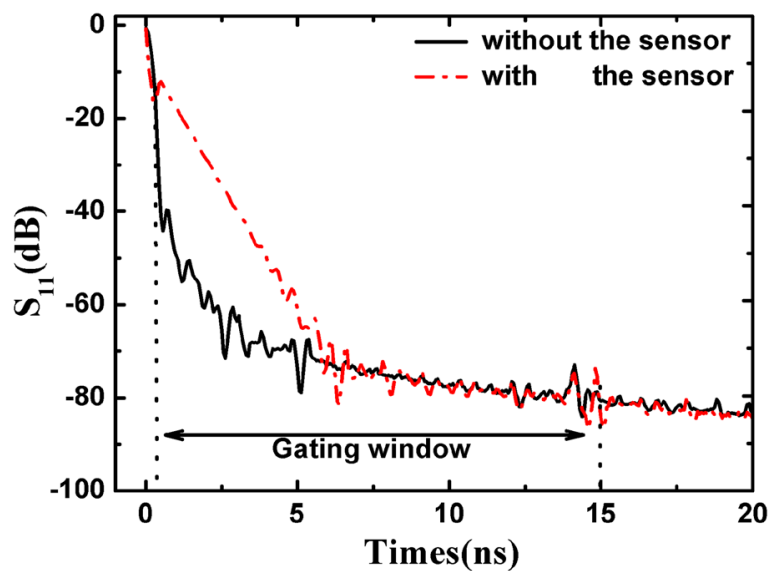

FIG. 5. Measured TD responses of OEWG with and without the sensor.

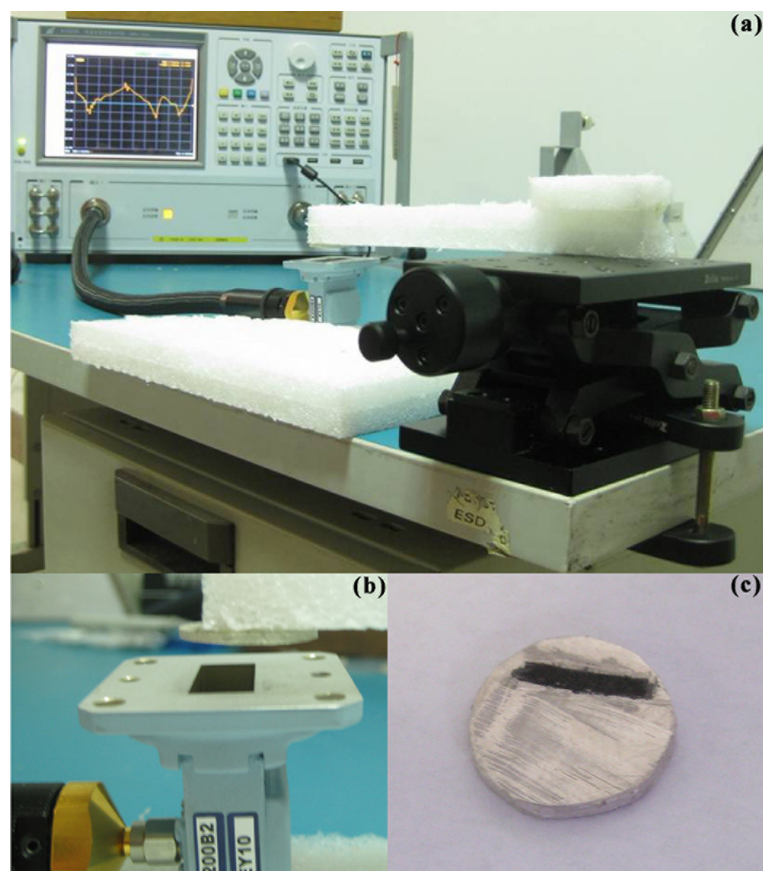

FIG. 6. (a) Side view of the measurement system, (b) side view of the resonator is placed above the OEWG, (c) top view of the fabricated resonator/antenna.

In the measurement, the resonator/antenna is placed above the OEWG using a plastic rod which was fixed on a lifting table. The sensing distance between the resonator/antenna and the OEWG can be manually controlled, as shown in Fig. 6. The AV3629D is connected to the OEWG to obtain $\mathrm{S}_{11}$ responses before and after the TD gating. The measured $\mathrm{S}_{11}$ after gating for different sensing distances is shown in Fig. 7. For distances from 2 to $20 \mathrm{~mm}$, the reflected spectrum exhibits peaks within $9.7-9.78 \mathrm{GHz}$, which is smaller than the simulation result due to the measuring error of the dielectric constant of SiCN ceramic. When the distance from the OEWG to the resonator/antenna increases, the level of the received signal decreases. Such decrease could be attributed to the decrease of $\mathrm{Q}_{\mathrm{L}}$, once the distance exceeded $20 \mathrm{~mm}, \mathrm{Q}_{\mathrm{L}}$ is too low to format resonance. It can be improved by decreasing the dielectric loss of SiCN ceramic, which is the work we are focus on now.

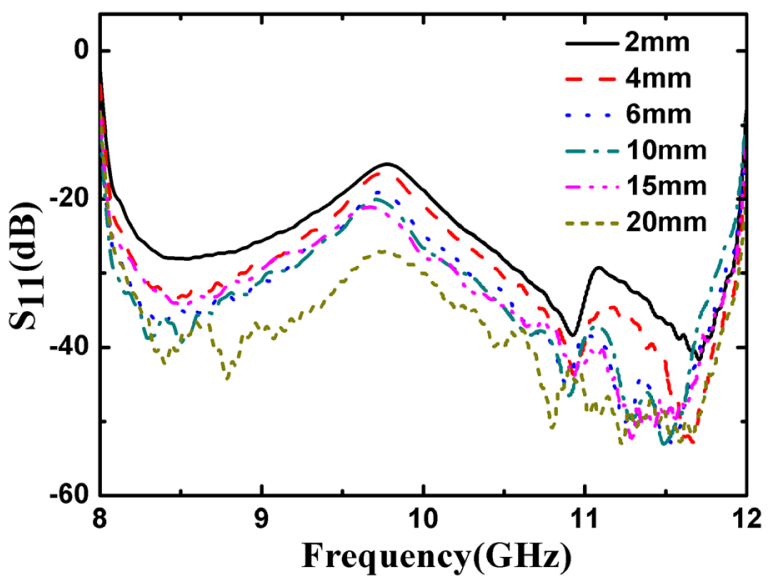

FIG. 7. Measured $\mathrm{S}_{11}$ response for each sensing distance after TD gating.

In summary, we investigated the effect of various parameters of a cavity RF resonator on the Q-factor and resonant frequency. Based on the simulation results, a compact passive wireless sensor was designed and fabricated by using high-temperature-stable SiCN ceramic. We demonstrated that the sensor can be wirelessly detected at distances up to $20 \mathrm{~mm}$. Combining with SiCN stable material, this sensor system can have a wide use in turbine engine, such as rotating engine blades.

Financial support from the Natural Science Foundation of China (51175444, 51075344, and 61274120), the Fundamental Research Funds for the Central Universities (Xiamen University, 2011121002), Xiamen Municipal Bureau of Science and Technology (3502Z20126006 and 3502Z20123008), New Century Excellent Talents in Fujian Province University, and Shenzhen City Science and Technology Innovation Committee (JCYJ20120618155425009) are acknowledged.

${ }^{1}$ M. A. Fonseca, J. M. English, and M. G. Allen, J. Microelectromech. Syst. 11(4), 337 (2002).

${ }^{2}$ F. R. Juang, Y. K. Fang, Y. T. Chiang, T. H. Chou, and C. I. Lin, IEEE Sens. J. 11(1), 150 (2011)

${ }^{3}$ A. Cagliani, L. M. Fischer, J. Lyager, and Z. J. Davis, Sens. Actuators B 160(1), 1250 (2011).

${ }^{4}$ L. S. Pakula, H. Yang, H. T. M. Pham, P. J. French, and P. M. Sarro, J. Micromech. microeng. 14(11), 1478-1483 (2004).

${ }^{5}$ D. H. Lee, K. H. Park, L. Y. Hong, and D. P. Kim, Sens. Actuators, A 135(2), 895 (2007).

${ }^{6}$ L. Liew, W. Zhang, V. M. Bright, L. An, M. L. Dunn, and R. Raj, Sens. Actuators A 89(1-2), 64 (2001).

${ }^{7}$ E. J. Connolly, B. Timmer, H. T. M. Pham, J. Groeneweg, P. M. Sarro, W. Olthuis, and P. J. French, Sens. Actuator B 109(1), 44 (2005).

${ }^{8}$ H. X. Zhang, H. Guo, Y. Wang, G. B. Zhang, and Z. H. Li, J. Micromech. Microeng. 17(3), 426 (2007).

${ }^{9}$ H. T. Cheng, S. Ebadi, X. H. Ren, Y. Yusuf, and X. Gong, in IEEE International Symposium on Antennas and Propagation (APSURSI), Spokane, WA, USA, 3-8 July, 2011, pp. 1350-1353.

${ }^{10}$ H. T. Cheng, S. Ebadi, and X. Gong, IEEE Antennas Wireless Propag. Lett. 11, 369 (2012).

${ }^{11}$ G. S. Chung, Microelectron. J. 38(8-9), 888 (2007).

${ }^{12}$ Y. G. Wang, Y. Fan, L. G. Zhang, W. G. Zhang, and L. N. An, Scr. Mater. 55(4), 295 (2006).

${ }^{13}$ L. N. An, Y. G. Wang, L. Bharadwaj, L. G. Zhang, Y. Fan, D. P. Jiang, Y. Sohn, V. H. Desai, J. Kapat, and L. C. Chow, Adv. Eng. Mater. 6(5), 337 (2004).

${ }^{14}$ Y. G. Wang, W. F. Fei, Y. Fan, L. G. Zhang, W. G. Zhang, and L. N. An, J. Mater. Res. 21(7), 1625 (2006). 
${ }^{15}$ R. Riedel, L. M. Ruwisch, L. N. An, and R. Raj, J. Am. Ceram. Soc. 81(12), 3341 (1998).

${ }^{16}$ Y. S. Wang, T. Jiang, L. G. Zhang, and L. N. An, J. Am. Ceram. Soc. 92(7), 1603 (2009).

${ }^{17}$ P. A. Ramakrishnan, Y. T. Wang, D. Balzar, L. N. An, C. Haluschka, R. Riedel, and A. Herman, Appl. Phys. Lett. 78(20), 3076 (2001).

${ }^{18}$ Y. S. Wang, L. G. Zhang, Y. Fan, D. P. Jiang, and L. N. An, J. Mater. Sci. 44(11), 2814 (2009).

${ }^{19}$ L. G. Zhang, Y. S. Wang, Y. Wei, W. X. Xu, D. J. Fang, L. Zhai, K. Lin, and L. N. An, J. Am. Ceram. Soc. 91(4), 1346 (2008).

${ }^{20}$ Y. G. Wang, J. Ding, W. Feng, and L. N. An, J. Am. Ceram. Soc. 94(2), 359 (2011).

${ }^{21}$ R. Riedel, L. Toma, and E. Janssen, J. Am. Ceram. Soc. 93(4), 920 (2010).
${ }^{22}$ X. H. Ren, S. Ebadi, Y. H. Chen, L. N. An, and X. Gong, IEEE Trans. Microwave Theory Tech. 61(2), 960 (2013).

${ }^{23}$ X. H. Ren, S. Ebadi, Y. H. Chen, L. N. An, and X. Gong, in 12th Annual IEEE Wireless and Microwave Technology Conference (WAMICON), Clearwater Beach, FL, 18-19 April, 2011, pp. 1-5.

${ }^{24}$ R. B. Yang, C. Y. Tsay, D. S. Hung, W. F. Liang, Y. D. Yao, and C. K. Lin, J. Appl. Phys. 105, 07A528 (2009).

${ }^{25} \mathrm{M}$. Yu, Y. X. Que, Z. R. Ni, and F. Xiao, in IEEE International Conference on Computer Science and Automation Engineering (CSAE), Zhangjiajie, China, 25-27 May, 2012, Vol. 3, pp. 327-330.

${ }^{26}$ G. L. Xiao and H. Y. Yang, J. Semicond. 33(12), 122001 (2012).

${ }^{27}$ C. A. Balanis, Advanced Engineering Electromagnetic (John Wiley \& Sons, New York, 1989), p.495.

${ }^{28}$ P. J. Pupalaikis, K. Doshi, R. Delbue, and A. Sureka, U.S. patent 2011/0191054 A1 (4 August 2011). 